\title{
Training in Infectious Diseases: Report of a Joint Working Party of the Royal College of Physicians and the Royal College of Pathologists
}

\author{
P.D. Welsby \\ Regional Infectious Diseases Unit, City Hospital, Greenbank Drive, Edinburgh EH10 5SB, UK
}

Interest in infections and infectious diseases has escalated in recent years because of advances in technology, emergence of new diseases, new treatments of pathogens, and advances in medical treatment which have induced immunodeficiency as a side effect.

In the past the separation of roles of doctors in dealing with infection was clear. Clinicians were based in isolation hospitals (usually on the outskirts of towns and adjacent to cemeteries), and bacteriologists were mostly confined to laboratories. In the United States the pattern of evolution began later and was different with "laboratory based clinicians' fulfilling the two roles.

In the United Kingdom career advice was easy to give; clinicians should be trained in general medicine and have as much clinical experience in general medicine and infectious diseases as possible, whereas bacteriologists should concentrate on bench work. Both approaches are now certainly outdated and inappropriate. New advice is required because there is a spectrum of careers with extremes ranging from clinical service orientated clinicians or microbiologists with interests in research through to University or MRC researchers with secondary involvement in clinical medicine.

Accordingly, a Joint Working Party has issued its advice. ${ }^{1}$ The advice is heavyweight - one Fellow of the Royal Society, five professors and two doctors: it would be unwise for a light-weight mere consultant such as myself to gainsay such wisdom!

In summary it is recommended that (1) Infectious Disease Teams should be established in each Health District. (2) The number of Regional Infec-

\section{References}

1. Training in Infectious Diseases: Report of a Joint Working Party of the Royal College of Physicians and the Royal College of Pathologists. May 1990. tious Diseases Units should be increased, complemented by first class laboratories. (3) The number of Infectious Disease Physicians should be increased to over sixty during the next five years. (4) Training and research programmes should be $\vec{\circ}$ increased. (5) Physicians should gain experience in a regionally approved centre, in tropical infections, 음 and microbiology with several additional options to be considered - additional clinical medicine, $\square$

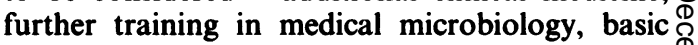
epidemiology, or research leading to a higher $\stackrel{\mathbb{}}{3}$ medical degree. (6) Microbiologists should, apart from higher specialist training, consider a cliniç post in infectious diseases, general medicine, pae $\dot{\&} \vec{\bullet}$ iatrics, sexually transmitted diseases or tropici infections; further training in epidemiology; labortatory training in molecular biology or research leading to a higher degree (interestingly, physicians will be expected to gain experience in medical microbiology, whereas for microbiologists a clini- $\stackrel{\mathbb{Q}}{\mathscr{Q}}$ cal post is only one of three options).

Implementation of the advice proffered con- $\frac{\overline{0}}{3}$ stitutes much more than a creeping development $\frac{J}{J}$ that could be sustained by any Health District; it will require central funding from the Department of Health. Surprisingly, even in the current political 3 and financial climate of the National Health Service, this is not impossible. Indeed the Acheson 3 . Report ${ }^{2}$ recommended the creation of Consultants $\delta$ in Communicable Disease Control - and these are $₹$ being created. The time is right for bright young $ᄋ$ doctors to initiate a career in clinical or research aspects of infection and infectious diseases.

2. Public Health in England. Report of the Committee of Inquiry into the future development of the Public Health Function. HMSO. London. 1988. CM289. 